\title{
Localization and assembly of proteins comprising the outer structures of the Bacillus anthracis spore
}

Correspondence
Adam Driks
adriks@lumc.edu

Received 15 August 2008

Revised 24 November 2008

Accepted 12 December 2008

\author{
Rebecca Giorno, ${ }^{1} \dagger$ Michael Mallozzi, ${ }^{1}$ Joel Bozue, ${ }^{2}$ Krishna- \\ Sulayman Moody, ${ }^{2}$ Alex Slack, ${ }^{1}$ Dengli Qiu, ${ }^{3}$ Rong Wang, ${ }^{3}$ \\ Arthur Friedlander, ${ }^{4}$ Susan Welkos ${ }^{2}$ and Adam Driks ${ }^{1}$ \\ ${ }^{1}$ Department of Microbiology and Immunology, Loyola University Medical Center, Maywood, IL \\ 60153, USA \\ ${ }^{2}$ Bacteriology Division, United States Army Medical Research Institute of Infectious Diseases, Fort \\ Detrick, Frederick, MD 21702-5011, USA \\ ${ }^{3}$ Department of Biological, Chemical, and Physical Sciences, Illinois Institute of Technology, \\ Chicago, IL 60616, USA \\ ${ }^{4}$ Headquarters, United States Army Medical Research Institute of Infectious Diseases, Fort Detrick, \\ Frederick, MD 21702-5011, USA
}

\begin{abstract}
Bacterial spores possess a series of concentrically arranged protective structures that contribute to dormancy, survival and, ultimately, germination. One of these structures, the coat, is present in all spores. In Bacillus anthracis, however, the spore is surrounded by an additional, poorly understood, morphologically complex structure called the exosporium. Here, we characterize three previously discovered exosporium proteins called ExsFA (also known as BxpB), ExsFB (a highly related paralogue of exs $F A / b x p B$ ) and lunH (similar to an inosine-uridine-preferring nucleoside hydrolase). We show that in the absence of ExsFA/BxpB, the exosporium protein BclA accumulates asymmetrically to the forespore pole closest to the midpoint of the sporangium (i.e. the mother-cell-proximal pole of the forespore), instead of uniformly encircling the exosporium. ExsFA/BxpB may also have a role in coat assembly, as mutant spore surfaces lack ridges seen in wild-type spores and have a bumpy appearance. ExsFA/BxpB also has a modest but readily detected effect on germination. Nonetheless, an exs $F A / b x p B$ mutant strain is fully virulent in both intramuscular and aerosol challenge models in Guinea pigs. We show that the pattern of localization of ExsFA/BxpB-GFP is a ring, consistent with a location for this protein in the basal layer of the exosporium. In contrast, ExsFB-GFP fluorescence is a solid oval, suggesting a distinct subcellular location for ExsFB-GFP. We also used these fusion proteins to monitor changes in the subcellular locations of these proteins during sporulation. Early in sporulation, both fusions were present throughout the mother cell cytoplasm. As sporulation progressed, GFP fluorescence moved from the mother cell cytoplasm to the forespore surface and formed either a ring of fluorescence, in the case of ExsFA/BxpB, or a solid oval of fluorescence, in the case of ExsFB. lunH-GFP also resulted in a solid oval of fluorescence. We suggest the interpretation that at least some ExsFB-GFP and lunH-GFP resides in the region between the coat and the exosporium, called the interspace.
\end{abstract}

\section{INTRODUCTION}

The bacilli and clostridia encompass a large number of species that produce highly resistant dormant cells, called

tPresent address: College of Biological Sciences, Louisiana Tech University, Ruston, LA 71270, USA.

Abbreviations: AFM, atomic force microscopy; IFM, immunofluorescence microscopy; IM, intramuscular; TEM, thin-section electron microscopy.

A supplementary table listing PCR primers used in this study is available with the online version of this paper. spores, in response to stress (Fritze, 2004; Nicholson, 2002). Prominent among these species is Bacillus anthracis, which has played a central historical role in our understanding of the transmission of disease and the mechanisms of toxin action, and which has reemerged as a serious threat to human life in light of its utility as a biological weapon (Alibek, 1999; Koch, 1876; Mock \& Fouet, 2001). Because the B. anthracis spore is the infectious particle for the disease anthrax, a deeper understanding of spore composition, assembly and function could be very useful in combating this threat. 
Spores from diverse Bacillus species possess a common architecture. Surrounding the core, which houses the DNA and protective DNA-binding proteins called small acidsoluble spore proteins (SASPs) (Setlow, 2006), is a specialized peptidoglycan called the cortex (Dowd et al., 2008; Popham, 2002). The cortex, in turn, is housed in a complex multilayered protein shell called the coat (Aronson \& Fitz-James, 1976; Warth et al., 1963). From studies in Bacillus subtilis, we know that the coat protects the spore against a variety of harmful molecules and facilitates germination, the process by which spores leave the dormant state and resume vegetative growth (Moir et al., 2002).

In some species, including B. subtilis, the coat is the outermost spore structure. In others, such as B. anthracis, spores possess an additional structure called the exosporium, which encases the entire spore. A thin basal layer appears to be a structural feature shared by exosporia of most or all species (Aronson \& Fitz-James, 1976; Holt \& Leadbetter, 1969). In some species, such as Bacillus megaterium, this layer is relatively thick (Aronson \& Fitz-James, 1976; A. Driks, unpublished observations; Holt \& Leadbetter, 1969; Vary, 1994). In others, such as B. anthracis and Bacillus cereus, a series of fine hair-like projections (also called a nap) extend a short distance from the basal layer. A striking feature of the $B$. anthracis exosporium is the significant space between the exosporium and the coat, a region we refer to as the interspace. Although no attachment points between the two structures are evident in conventional thin-section electron micrographs, such connections must exist in order for the exosporium to have been able to assemble around the spore.

The function of the exosporium is currently an area of active investigation. Efforts to identify its purpose are complicated by its presence in a taxonomically diverse subset of species that includes non-pathogenic organisms such as B. megaterium and Bacillus odysseyi (La Duc et al., 2004; Vary, 1994). Nonetheless, insight into possible exosporium functions has come from recent studies that indicate that the exosporium mediates adhesion to certain eukaryotic cell types representative of host tissues, provides some degree of resistance to the oxidative burst produced by macrophages in culture, and helps moderate the innate immune response to spores (Basu et al., 2007; Bozue et al., 2007b; Weaver et al., 2007). Additionally, the major exosporial protein BclA has been shown to mediate the phagocytosis of spores via interaction with the macrophage cell-surface integrin Mac-1 (Oliva et al., 2008). These functions could provide advantages to spores during pathogenesis and in a variety of niches other than that of an infected host.

About 20 exosporium-associated proteins and glycoproteins have been identified from analyses of $B$. anthracis and B. cereus (Redmond et al., 2004; Steichen et al., 2003; Sylvestre et al., 2002; Todd et al., 2003; Waller et al., 2005). In addition, other, less well-characterized molecules are also present, including lipids and carbohydrates (Bozue et al., 2005; Fox et al., 2003; Matz et al., 1970). The bestcharacterized $B$. anthracis exosporium protein is BclA, which is on the exosporium surface, is highly immunogenic, and is a major structural component of the hair-like projections (referred to below as 'projections') (Boydston et al., 2005; Rety et al., 2005; Steichen et al., 2003, 2005; Sylvestre et al., 2002, 2003, 2005). Several other exosporium proteins or candidate exosporium proteins have been characterized in B. anthracis. ExsFA (or BxpB) has also been shown to reside in the $B$. anthracis basal layer, and to have at least a partial role in the formation of projections and in BclA deposition (Steichen et al., 2005; Sylvestre et al., 2005). ExsFB, a paralogue of ExsFA/BxpB, also has a role in exosporium formation, since exs $F A / \operatorname{bxp} B$ exs $F B$ double mutant spores have a more severe exosporium defect than exsFA/bxpB mutant spores (Sylvestre et al., 2005). The B. anthracis proteins CotY and ExsY (orthologues of the B. subtilis coat proteins $\operatorname{Cot} Y$ and $\operatorname{Cot} Z$ ) have also been found in the exosporium (Redmond et al., 2004). ExsY has a role in exosporium assembly, as exs $Y$ mutant spores possess only a fragment of this structure (Boydston et al., 2006). The view that these proteins are together in the exosporium is supported by the finding that ExsFA/ $\mathrm{BxpB}$ is present as part of a complex with BclA and ExsY (Redmond et al., 2004). The exosporium glycoprotein BclB has also been shown to play an important role in exosporium stability, as $b c l B$ mutant spores assemble only partial exosporia, or lack the structure entirely (Thompson et al., 2007).

Some spore proteins play roles in assembly of both the coat and exosporium. The B. anthracis coat protein CotE directs assembly of at least one coat protein other than itself (Giorno et al., 2007). In addition, in most cotE mutant sporangia, an exosporium is synthesized, but accumulates in the mother cell without encircling the forespore. This and other data support the inference that CotE directs the attachment of the exosporium to the forespore surface.

Some exosporium proteins are orthologues of previously identified enzymes. For example, alanine racemase (AlR) and inosine hydrolase (IunH) are present in B. anthracis and $B$. cereus exosporia, consistent with a role for the exosporium in the modification of germinant molecules (Boydston et al., 2006; Redmond et al., 2004; Steichen et al., 2007; Todd et al., 2003). Arginase activity is also present in the $B$. anthracis exosporium, and plays a role in protection against oxidative bursts generated by macrophages, as already discussed (Weaver et al., 2007).

In this work, we further characterize ExsFA/BxpB and show evidence to suggest that ExsFB and IunH do not entirely colocalize with ExsFA/BxpB. We show that ExsFA/BxpB affects spore surface morphology and germination, localizes to the exosporium basal layer, and plays a role in distributing BclA throughout the exosporium surface. Finally, we demonstrate that, in two animal challenge models, ExsFA/BxpB is dispensable for virulence. 


\section{METHODS}

General methods. Escherichia coli strains were cultured in LuriaBertani (LB) medium and antibiotics were used at standard concentrations (Sambrook et al., 1989). For B. anthracis, erythromycin, tetracycline and kanamycin were used at concentrations of 5, 5 and $20 \mu \mathrm{g}$ $\mathrm{ml}^{-1}$, respectively. Sporangia and spores from the Sterne 34F2 strain and Sterne 34F2-derived stains of $B$. anthracis were prepared by exhaustion in Difco sporulation medium (DSM) (Lai et al., 2003), unless stated otherwise. Sporulation at room temperature was performed using either $2 \times$ SG medium (Harwood \& Cutting, 1990) (for fluorescence microscopic analysis) or DSM [for immunofluorescence microscopy (IFM)], as indicated. We prepared Ames strain spores by culture in Leighton-Doi broth (Ivins et al., 1990; Leighton \& Doi, 1971). Time $0\left(t_{0}\right)$ of sporulation was defined as the first point at which the culture leaves exponential-phase growth. We carried out further purification of Ames strain spores by centrifugation through Hypaque76 gradients (Nycomed). All preparations possessed $>95 \%$ spores. For germination and virulence studies, we diluted the spores in sterile water, heated them at $65{ }^{\circ} \mathrm{C}$ for $30 \mathrm{~min}$, and then kept them on ice. Electron and atomic force microscopy (AFM) were carried out according to Catalano et al. (2001) and Chada et al. (2003), respectively.

Recombinant DNA methods. Recombinant DNA techniques were performed using standard methodologies (Sambrook et al., 1989) or according to manufacturer's instructions. Strains and plasmids are referenced or described in Table 1. Primers are referenced in Supplementary Table S1. To construct plasmid pMR6, we first used PCR to amplify approximately $1 \mathrm{~kb}$ stretches of DNA on either side of exsFA/bxpB, using primers OL298 and OL299 (to amplify the upstream region), and primers OL300 and OL301 (to amplify the downstream region). The PCR products were cloned into plasmid pMR1, such that they flanked the plasmid-borne kanamycinresistance marker. To do this, we digested the upstream PCR product and PMR1 with SacI and NotI, and ligated the products. We then digested the resulting plasmid and the downstream PCR product with Bam HI and SalI, and ligated the resulting digestion products together. To generate strains bearing fusions of genes to $g f p$, we first built plasmids (pAS1 and pRG30) bearing $g f p$. To build pAS1, we PCRamplified $g f p$ from plasmid pKL147 (Lemon \& Grossman, 1998) with primers OL471 and OL472, digested the PCR product and pUTE-29 with BamHI and HindIII, and ligated the resulting fragments. To build pRG30 we digested pAS1 with HindIII and SmaI, and ligated the $g f p$-bearing fragment into similarly digested $\mathrm{pKS} 1$. We then used pAS1 or pRG30 to build a set of plasmids bearing $g f p$ fusions to different spore proteins, which were designed to integrate into the chromosome. To build plasmid pAS4, we first PCR-amplified the $3^{\prime}$ end of exsFA/bxpB with primers OL504 and OL505. We digested the PCR product with BamHI and EcoRV, and pAS1 with BamHI and $P m e I$, and ligated these together. To build pAS2 we first amplified the $3^{\prime}$ end of $i u n H$ with primers OL476 and OL498. We digested the PCR product with BamHI and EcoRV, and pAS1 with BamHI and PmeI, and ligated the digestion products. To build pRG25 we digested pAS4 with BamHI and HindIII, and ligated it to BamHI- and HindIIIdigested plasmid pEO-3 (Mendelson et al., 2004). To build pRG31 we first amplified the $3^{\prime}$ end of exsFB with primers OL846 and OL847. We digested the PCR product with NotI and EcoRV, and pRG30 with NotI and PmeI, and ligated the digestion products.

To build plasmid pEO-3-exsFA/BxpB, we PCR-amplified an internal fragment of $\operatorname{exs} F A / b x p B$ corresponding to nucleotides 105-390, using primers ExsF-KpnI and ExsF-HindIII. We digested this product with $K p n I$ and HindIII, and ligated it into similarly digested plasmid pEO-3.

Construction of $\boldsymbol{B}$. anthracis mutant strains. We transformed the Sterne strain by electroporation (Koehler et al., 1994), using one or another of the plasmids described above. To build RG124 and RG130, we isolated strains bearing a chromosomally integrated copy of the plasmid by culturing transformants bearing plasmid pMR6 or pAS2 in LB medium for several days, diluting the culture 1:10 twice a day, and plating on LB agar supplemented with either kanamycin (to isolate the $\operatorname{exs} F A / \operatorname{bxp} B$ single-integration mutant) or tetracycline (to isolate the iunH-gfp-bearing mutant, strain RG130). We then screened individual colonies for plasmid integration by PCR. To generate the exsFA/bxpB deletion strain, an additional reverse reciprocal excision had to take place. Therefore, we cultured a kanamycin- and tetracycline-resistant colony in LB medium over the course of several days, as described. We screened samples of the culture until we were able to isolate a kanamycin-resistant and tetracycline-sensitive colony, which became strain RG124. To build RG151, we introduced pRG25 into the Sterne strain and selected for chromosomally integrated plasmids by plating on solid medium with erythromycin, at the nonpermissive temperature as described previously (Mendelson et al., 2004). To build RG155, we introduced pRG31 into the Sterne strain and selected for chromosomally integrated plasmids as described elsewhere (Shatalin \& Neyfakh, 2005). To build a version of the Sterne strain in which bclA is inactivated (Sterne-JAB-13), we followed the approach of Bozue et al. (2007b). Each strain was confirmed by PCR analysis.

Phage transduction. To generate strains RG157, RG158 and RG169 we used the CP51ts generalized transducing phage (Thorne, 1968). Donor strains where grown overnight at $37^{\circ} \mathrm{C}$ in LB medium and $100 \mu \mathrm{l}$ aliquots of cell culture were infected with $100 \mu \mathrm{l}$ of 10 fold serially diluted solutions of phage. Infected cells were then plated onto solid PA medium (Thorne, 1968) using the soft-agar overlay technique. After incubation at $30{ }^{\circ} \mathrm{C}$ in a humidity chamber for up to 2 days, plaques were collected and the cell debris was removed by centrifugation. The phage-containing supernatant was collected and filtered through either a 0.2 or a $0.45 \mu \mathrm{m}$ pore-size filter and serially diluted as before. The recipient strain was grown overnight in brain-heart infusion (BHI) broth supplemented with $0.5 \%(\mathrm{v} / \mathrm{v})$ glycerol, transferred into fresh medium, and grown for 6-7 h. Of this culture, $1 \mathrm{ml}$ was infected with $100 \mu \mathrm{l}$ of each phage dilution, incubated at room temperature without shaking for $30 \mathrm{~min}$, and then in a roller drum for a further $2 \mathrm{~h}$. Finally, $0.1-$ $1.0 \mathrm{ml}$ of infected cells was plated onto LB plates supplemented with tetracycline for strains RG157 and RG158, or kanamycin for strain $\mathrm{RG} 169$, and incubated at $37^{\circ} \mathrm{C}$ (to cure the phage and allow for marker expression).

Fluorescence and IFM. We analysed Sterne strain spores and sporangia according to Pogliano et al. (1995) using a Leica DM IRB fluorescence microscope equipped with a MagnaFire cryo-cooled charge-coupled device (CCD) camera. Spores were water-washed prior to adherence to slides, and sporangia were treated with methanol at $-20{ }^{\circ} \mathrm{C}$ for $5 \mathrm{~min}$ after adherence to access interior epitopes. Images were processed with Adobe Photoshop 7.0 software. To detect GFP fusion proteins, rabbit anti-GFP antibodies (Promega) were used at a 1:2000 dilution, and Alexa Fluor 568-conjugated goat anti-rabbit antibodies (Molecular Probes) were used at a $1: 300$ dilution. To detect BclA, we used the anti-BclA mAb BA-MAB 5 (Critical Reagents Program, Department of Defense) at a $1: 80000$ dilution and Alexa Fluor 568-conjugated goat anti-mouse antibodies (Moleular Probes) at a 1:300 dilution. Chromosomes were visualized using the DNA-specific probe Hoechst 33342 (Sigma) as previously described (Catalano et al., 2001). Data presented are representative of more then 150 spores observed.

Germination assays. The spectrofluorometric germination assay was done according to Welkos et al. (2004). The tetrazolium overlay assay was done according to Giorno et al. (2007). We monitored germination [using spores from three independent sporulations 
Table 1. Bacterial strains and plasmids used in this study

\begin{tabular}{|c|c|c|}
\hline Strain or plasmid & Genotype or description & Source or reference \\
\hline \multicolumn{3}{|l|}{ Strains } \\
\hline \multicolumn{3}{|c|}{ Sterne strain and derivatives } \\
\hline RG1 & Sterne wild-type $34 \mathrm{~F} 2$, attenuated & P. J. Jackson* \\
\hline RG124 & $\operatorname{exs} F A / b x p B:: k m$ & This study \\
\hline RG130 & iunH $\Omega$ pAS2 & This study \\
\hline RG151 & $\operatorname{exs} F A / b x p B \Omega$ pRG 25 & This study \\
\hline RG155 & $\operatorname{exs} F B \Omega p R G 31$ & This study \\
\hline RG157 & $\cot E:: k m$ exsFA/bxpBSpRG25 & This study \\
\hline RG158 & $\cot E:: k m$ exsFB $\Omega$ pRG31 & This study \\
\hline RG169 & $b c l A:: k m$ exsFB $\Omega p R G 31$ & This study \\
\hline Sterne-JAB-13 & bclA $:: \mathrm{km}$ & This study \\
\hline \multicolumn{3}{|c|}{ Ames strain and derivatives } \\
\hline Ames strain & Wild-type, fully virulent & Little \& Knudson (1986) \\
\hline Ames-JAB-5 & $\operatorname{exs} F A / b x p B \Omega p E O 3-\operatorname{exs} F A / b x p B$ & This study \\
\hline \multicolumn{3}{|l|}{ E. coli strains } \\
\hline DH $5 \alpha$ & Cloning host & Laboratory collection \\
\hline GM1684 & dam used for transformation of Sterne strain & T. Koehler \\
\hline GM2163 & dam $\mathrm{dcm}$ used for transformation of Ames strain & New England Biolabs \\
\hline \multicolumn{3}{|l|}{ Plasmids } \\
\hline \multicolumn{3}{|c|}{ Bifunctional plasmids } \\
\hline pAS1 & $\mathrm{Ap}^{\mathrm{r}}$ in E. coli, $\mathrm{Tc}^{\mathrm{r}}$ in B. anthracis for construction of $3^{\prime} g f p$ fusions & This study \\
\hline pAS2 & iun $H-g f p$ fusion vector & This study \\
\hline pAS4 & exsFA/bxpB-gfp fusion vector & This study \\
\hline $\mathrm{pEO} 3$ & E. coli/Bacillus shuttle vector & Mendelson et al. (2004) \\
\hline $\mathrm{pEO} 3-b x p B / e x s F$ & $\operatorname{exs} F A / b x p B$ inactivation vector & This study \\
\hline pJRS182 & Source of $\Omega k m-2$ & Perez-Casal et al. (1991) \\
\hline pKL147 & Source of $g f p$ mut 2 & Lemon \& Grossman (1998) \\
\hline pKS1 & Temperature-sensitive vector in $B$. anthracis & Shatalin \& Neyfakh (2005) \\
\hline pMR1 & Derivative of pUTE- 29 containing $\Omega \mathrm{km}-2$ from pJRS182 & Giorno et al. (2007) \\
\hline pMR6 & $\operatorname{exs} F A / b x p B$ deletion vector & This study \\
\hline pRG25 & $\operatorname{exs} F A / b x p B-g f p$ fusion vector & This study \\
\hline pRG30 & Derivative of $\mathrm{pKS} 1$ bearing $g f p$ & This study \\
\hline pRG31 & exsFB-gfp fusion vector & This study \\
\hline pUTE-29 & $\mathrm{Ap}^{\mathrm{r}}$ in E. coli, $\mathrm{Tc}^{\mathrm{r}}$ in B. anthracis & Koehler et al. (1994) \\
\hline
\end{tabular}

${ }^{\star}$ Lawrence Livermore National Laboratory, Livermore, CA, USA.

(prepared by culture in DSM)] via the loss of optical density assay according to Harwood \& Cutting (1990), except that to initiate germination, spores were resuspended at $\mathrm{OD}_{580} 0.1$ at room temperature in RPMI-BHI medium (Steichen et al., 2005).

Animal challenges. For intramuscular (IM) challenges, female Hartley Guinea pigs (350-400 g) (Charles River Laboratories) $(n=10)$ were given intramuscular injections of 1000 spores, representing the equivalent of 10 Ames $\mathrm{LD}_{50}$ (Ivins et al., 1994). We performed wholebody aerosol challenges as described previously (Cown et al., 1957; Friedlander et al., 1993; May, 1973) with an inhaled dose representing approximately 5 Ames $\mathrm{LD}_{50}$ and measured survival rates.

Statistical analysis. Survival rates and mean times to death were compared between each treatment group and control group by Fisher's exact test and Student's $t$ test, respectively, with permutation adjustment for multiple comparisons. All analyses were conducted using SAS version 8.2 (SAS Institute, SAS OnlineDoc, version 8). Data collected from the loss of optical density germination assay were analysed by the Mann-Whitney U test (Mann \& Whitney, 1947).

\section{RESULTS}

\section{Characterization of exsFA/bxpB mutant spores}

In the course of a proteomic analysis designed to discover spore coat proteins, we identified several previously described exosporium proteins (Lai et al., 2003; Redmond et al., 2004; Steichen et al., 2003; Todd et al., 2003). To better understand the role of one of these, ExsFA/BxpB, in spore function, we generated and characterized versions of the Ames and Sterne strains of $B$. anthracis in which exsFA/bxpB was inactivated (strains Ames-JAB-5 and RG124, respectively). Both strains grew and sporulated similarly to the corresponding wild-type strains. By thin-section electron microscopy (TEM), however, we found that the projections, or nap, extending from the exosporium were missing from spores of both mutant strains (data not shown), consistent with the 
findings of Steichen et al. (2005). However, Sylvestre et al. (2005) found that exsFA/bxpB mutant spores had fewer projections.

We also characterized the mutant spore surface by AFM. This is a non-optical imaging technology that can produce high-resolution images of cell surfaces without any fixation or other preparation (Fotiadis et al., 2002; Shao et al., 1996; Wang et al., 2007). We allowed Sterne strain or exsFA/bxpB mutant spores to air-dry and imaged at least 150 spores for each sample in the tapping mode (Chada et al., 2003). Using AFM, the coat surface can be distinguished from the exosporium surface by distinctive ridges that run along the coat surface (Chada et al., 2003; Plomp et al., 2004). In B. anthracis, the ridges usually appear in closely apposed pairs that are relatively narrow, rounded and of about equal width (Fig. 1a) (Chada et al., 2003; Giorno et al., 2007). The surface of $\operatorname{exs} F A / \operatorname{bxp} B$ mutant spores (from strain RG124) was distinct from that of wild-type, in that they lacked ridges and had a bumpy appearance (Fig. 1b, c). These results suggest that ExsFA/BxpB has a role in directing coat surface topography. Because we rarely observed exosporia on exsFA/bxpB mutant spores from strain RG124 we were unable to obtain good quality images of the mutant spore exosporium surface. Our inability to obtain images of the exosporium surface may be related to an earlier observation that the exosporium basal layer is unstable in exsFA/bxpB spores (Sylvestre et al., 2005).

Earlier reports have shown that at least some BclA is sporeassociated in $\operatorname{exs} F A / \operatorname{bxp} B$ mutant spores (Steichen et al.,
2005; Sylvestre et al., 2005). Therefore, BclA deposition can be divided into two phases: ExsFA/BxpB-dependent and ExsFA/BxpB-independent. To analyse the subcellular location of the ExsFA/BxpB-independent BclA during sporulation, we used IFM, with the anti-BclA mAb BAMAB-5, to monitor BclA localization in wild-type and exsFA/bxpB mutant cells that had completed forespore engulfment (known as sporangia) in the Sterne strain background. To visualize the orientation of the forespore and mother cell compartments, we analysed fixed and Hoechst 33342-stained cells by bright-field and fluorescence microscopy simultaneously. In these experiments, the forespore appears as an oval-shaped structure and the mother cell chromosome as a bright focus (Fig. 2a, BF/ DNA). We first analysed wild-type sporangia to determine when BclA would initially be detected by IFM. In this and subsequent IFM experiments, we analysed a minimum of 150 cells. After $4 \mathrm{~h}$ of sporulation, a time at which BclA is known to be expressed (Sylvestre et al., 2002), we did not detect BclA in sporangia (data not shown). After $7 \mathrm{~h}, \mathrm{BclA}$ was clearly localized around the forespore in wild-type sporangia (Fig. 2a). The same fluorescence pattern was seen in free spores (Fig. 2b). To confirm the specificity of the $\mathrm{mAb}$, we also examined a $b c l A$ mutant strain (Sterne-JAB13). Anti-BclA fluorescence was not detected in $b c l A$ mutant sporangia or spores (data not shown).

In $\operatorname{exs} F A / \operatorname{bxp} B$ mutant sporangia after $7 \mathrm{~h}$ of sporulation, the BclA localization pattern suggested that at least some of the protein was located in the mother cell (Fig. 2a). After $8 \mathrm{~h}, \mathrm{BclA}$ was localized exclusively around the forespore, in both wild-type and mutant strains. However, in the exsFA/
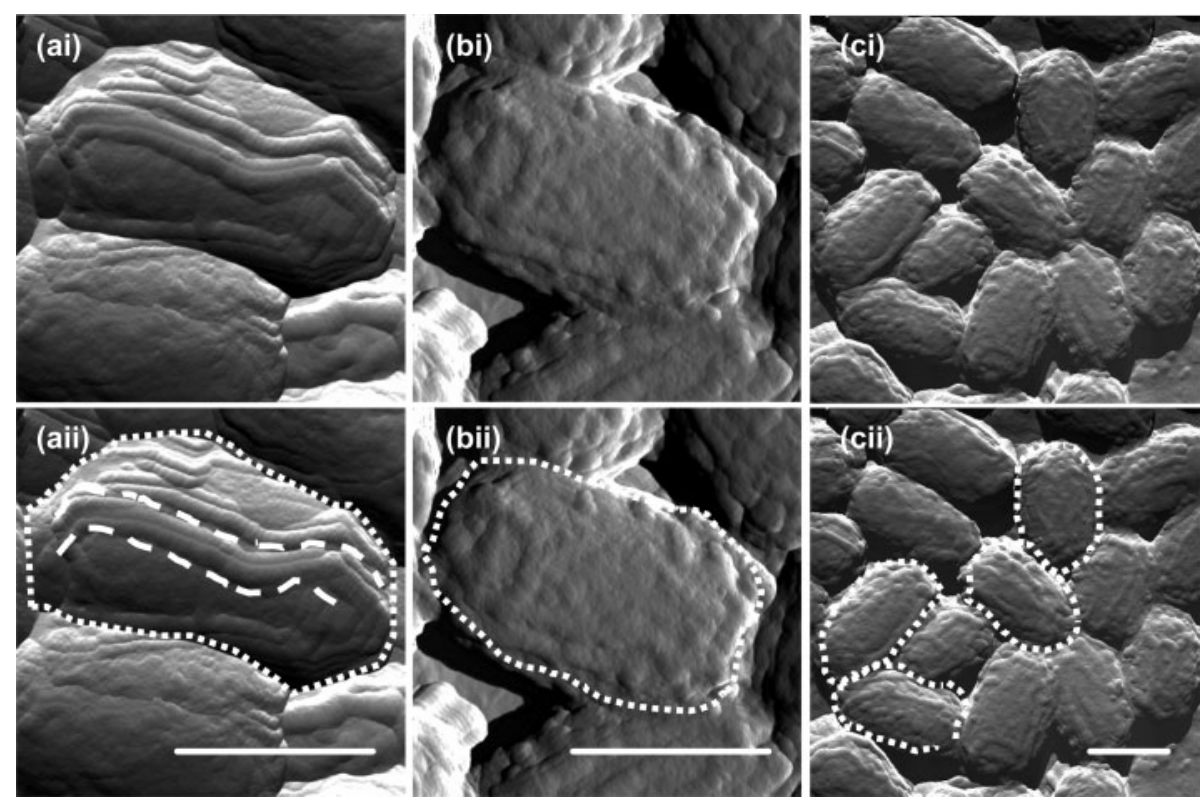

Fig. 1. Atomic force micrographs of Sterne strain spores of $B$. anthracis. (a) Wild-type Sterne and (b, c) RG124 (exsFA/bxpB) spores were analysed in the tapping mode. Bars, $1 \mu \mathrm{m}$. In panels (aii), (bii) and (cii), the white dotted lines indicate spore outlines and the white dashed lines indicate surface ridges. 
(a)

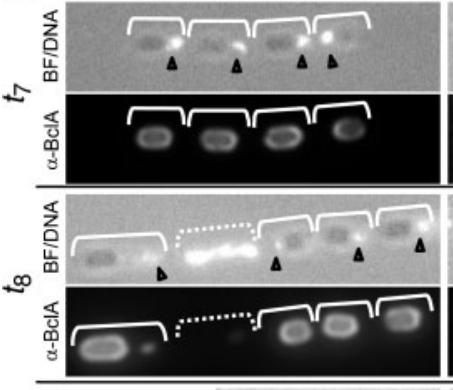

(b)
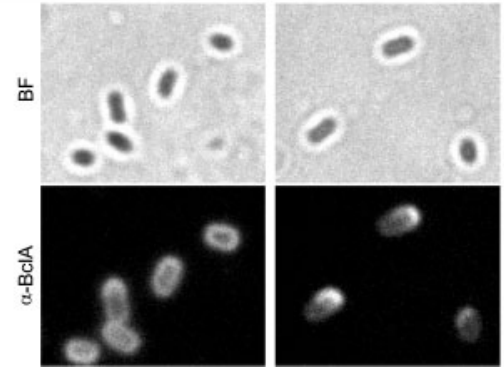

Fig. 2. Fluorescence microscopic analysis of the role of ExsFA/ $\mathrm{BxpB}$ in BclA deposition. (a) Sporangia from the Sterne strain (wild-type; WT) and strain RG124 (exsFA/bxpB) were harvested after 7 and $8 \mathrm{~h}$ of sporulation ( $t_{7}$ and $t_{8}$, respectively), fixed and treated with the anti-BclA mAb BA-MAB5 $(\alpha-B c \mid A)$. Bright-field microscopy and fluorescence microscopy (BF/DNA) were performed simultaneously so that the forespore and mother cell DNA (stained with Hoechst 33342 dye) could be visualized in a single image. The locations of individual cells are indicated with brackets. Mother cell chromosomes are indicated with arrowheads. The cell indicated by a dashed bracket (wild-type at $t_{8}$ ) did not sporulate, as indicated by the chromosome morphology. (b) Spores from the wild-type or RG124 (exsFA/bxpB) strains were harvested $24 \mathrm{~h}$ after the onset of sporulation and stained with the anti-BclA antibody BA-MAB-5. Corresponding bright-field (BF) images are shown for each immunohistograph $(\alpha-B c \mid A)$. Data shown are representative of a minimum of 150 cells observed for each sample and time point. We judged the immunostaining to be positive if at least $90 \%$ of the cells showed fluorescence. All negative control experiments showed fluorescence in fewer than $10 \%$ of cells.

$\operatorname{bxp} B$ mutant sporangia, BclA decoration was more intense at the edge of the forespore closest to the midpoint of the sporangium (i.e. the mother-cell pole of the forespore) (Fig. 2a). We found that BclA also localized in a polar fashion in free spores from the exsFA/bxpB mutant (Fig. $2 \mathrm{~b})$. This region of BclA decoration appears to coincide with the portion of the exosporium that forms first in sporulation, called the cap (Giorno et al., 2007; Ohye \& Murrell, 1973; Steichen et al., 2007). These unexpected results indicate a previously unrecognized polarity to $\mathrm{BclA}$ localization.

Our TEM analysis indicated that released exsFA/bxpB mutant spores do not possess projections (or nap) (data not shown), consistent with earlier results (Steichen et al., 2005). Nonetheless, as just discussed, at least some BclA is

forespore-localized in exsFA/bxpB mutant sporangia, as shown by IFM (Fig. 2a). The presence of foresporeassociated $\mathrm{BclA}$ in mutant cells raised the possibility that projections were also present (presumably, if this were true, the projections are lost during or just before spore release from the mother cell). To test this, we used TEM to determine whether projections could be detected in exsFA/ $\operatorname{bxp} B$ mutant sporangia after 6 and $8 \mathrm{~h}$ of sporulation, when the projections are readily visible in wild-type cells (Giorno et al., 2007; Steichen et al., 2007). We did not detect projections in exsFA/bxpB mutant cells (data not shown). Therefore either $\operatorname{exs} F A / b x p B$ mutant cells do not assemble projections, even transiently, or they are unstable. Overall, these data are consistent with the view that, while some BclA localizes in an ExsFA/BxpB-independent manner, this deposition is insufficient to maintain either a uniform shell of BclA or the formation of recognizable projections.

\section{Role of ExsFA/BxpB in spore functions}

The exosporium could have a role in germination or outgrowth (Redmond et al., 2004; Steichen et al., 2005). Therefore, we analysed the ability of exsFA/bxpB mutant spores to germinate and resume metabolism (known as outgrowth). We analysed early events in germination by measuring the rate and level of incorporation of the fluorescent dye Syto-9 (Welkos et al., 2004). We found that the initial dye uptake kinetics of the exsFA/bxpB spores from either the Sterne or the Ames background were identical to those of wild-type spores (Fig. 3a). However, after $4 \mathrm{~min}$, the rate of dye incorporation from the exsFA/ $b x p B$ spores was reduced, and after $60 \mathrm{~min}$, the $\operatorname{exs} F A / b x p B$ spores had not incorporated as much dye as the wild-type spores (Fig. 3a). This effect appeared to be more severe in the Ames background. We do not know the significance of this difference between the two strain backgrounds. The effect of the exsFA/bxpB mutation on dye uptake is not due solely to the reduction in spore-associated $\mathrm{BclA}$, since Ames spores entirely missing BclA (due to a bclA mutation) take up dye as well as wild-type spores (Bozue et al., 2007a). In previous work, germination of $\operatorname{exsFA/bxpB}$ mutant spores was measured using RPMI-BHI medium as a germinant (Steichen et al., 2005). Therefore, we also monitored germination by measuring the loss of optical density (Harwood \& Cutting, 1990) using this germinant. After $5 \mathrm{~min}$, the percentage loss of optical density of by $\operatorname{exs} F A / b x p B$ mutant spores (in the Sterne background, strain RG124) was lower than in wild-type, and remained so throughout the experiment (Fig. 3b). Although modest, the difference between wild-type and mutant spores in this assay was significant as determined by the Mann-Whitney $\mathrm{U}$ test $(P<0.01)$. Taken together, these results suggest that $\operatorname{exs} F A / b x p B$ spores have a defect in an early step of germination.

To determine whether an $\operatorname{exs} F A / b x p B$ mutation affects late events in germination and/or the resumption of metabol- 


\section{(a)}
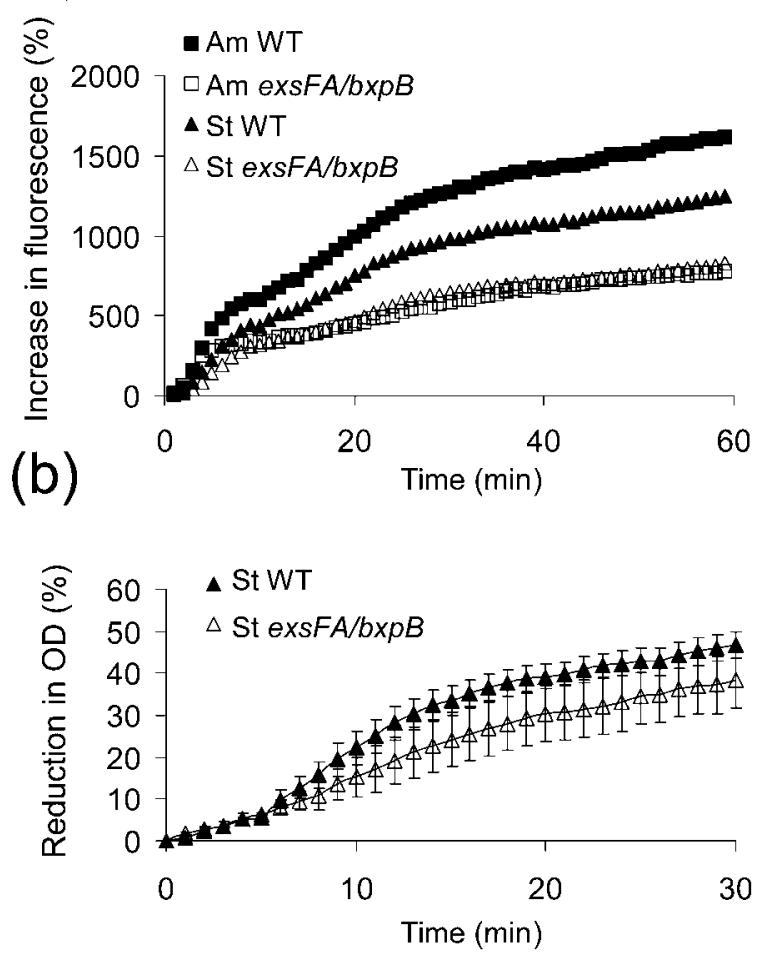

Fig. 3. Germination of wild-type (WT) and mutant spores. (a) Spores from wild-type Ames ( $\boldsymbol{\square})$, wild-type Sterne ( $\boldsymbol{\Lambda})$, AmesJAB-5 ( $\square)$ and RG124 ( $\triangle)$ strains were analysed by the fluorescence dye uptake assay. The percentage increase in fluorescence is the difference between the fluorescence in relative fluorescence units (RFU) at a given time in germination medium and the RFU at $t_{0}$, expressed as a percentage of the latter. (b) Spores from wild-type Sterne $(\boldsymbol{\Delta})$ and RG124 $(\triangle)$ were monitored over time for the loss of refractility by measuring the reduction in optical density. Both assays were done in triplicate. The data shown in (a) are representative of three independent experiments, and SEM values are shown in (b).

ism (outgrowth), we used a modified version of the tetrazolium overlay assay (Harwood \& Cutting, 1990; Giorno et al., 2007). Spores from exsFA/bxpB mutant strains, in either the Sterne or the Ames background (in RG124 and Ames-JAB-5, respectively), showed wild-type levels of outgrowth by this assay (data not shown).

To detect a role for ExsFA/BxpB in infection, we measured the ability of exsFA/bxpB mutant spores (from Ames-JAB5) to infect Guinea pigs by both IM and inhalational challenges. The mutant strain was fully virulent in both experiments (Fig. 4). There were no significant differences in mean time to death between strains by either the IM route $(P=0.2878)$ or the aerosol route $(P=0.5062)$ as measured by Student's $t$ test, nor were there any significant differences in survival rates between strains after infection by the aerosol route $(P=0.2105)$, as measured by Fisher's (a)

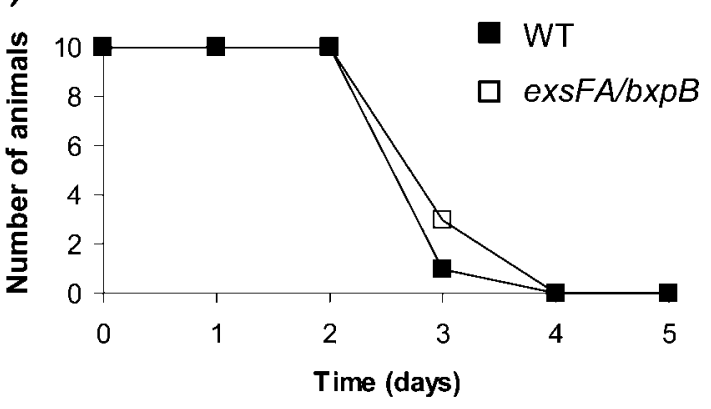

(b)

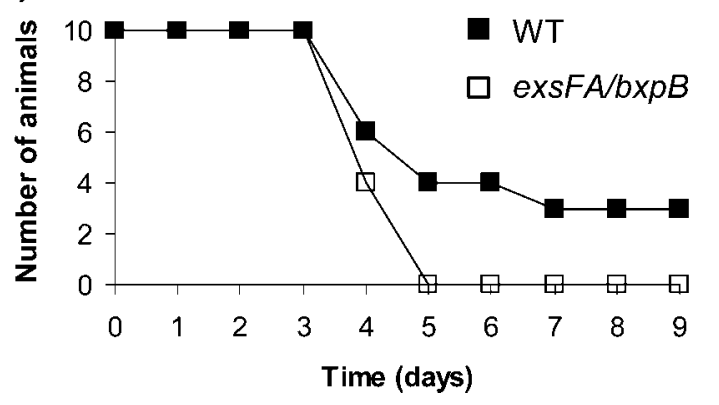

Fig. 4. Effect of exsFA/bxpB on virulence. Spores from the wildtype (WT) Ames strain ( $\boldsymbol{\square}$ ) or Ames-JAB-5 ( $\square$ ) were used in (a) Guinea pig IM or (b) Guinea pig inhalational challenge assays. Numbers of surviving animals are plotted.

exact test. There were no survivors in the IM-exposed group. These results are consistent with previous results (Bozue et al., 2007a; Sylvestre et al., 2002). Our results indicate that neither the germination defect nor the changes in spore composition and morphology of the $\operatorname{exs} F A / \operatorname{bxp} B$ Ames mutant detectably reduce disease using these two routes of infection.

\section{Subcellular localization and assembly of ExsFA/ BxpB and ExsFB}

To better understand the roles of ExsFA/BxpB and ExsFB in spore assembly and function, we examined their locations in living cells during sporulation. To do this, we built strains (in the Sterne background) bearing fusions of each protein to GFP, and examined them by fluorescence microscopy. Cells from strains bearing ExsFA/BxpB-GFP (RG151) and ExsFB-GFP (RG155) grew and sporulated normally, as judged by light microscopy (data not shown). We noted, however, that TEM showed that $\operatorname{exs} F A / b x p B-g f p$-bearing spores lacked projections, suggesting a role for the $\operatorname{ExsFA} / \mathrm{BxpB} \mathrm{C}$ terminus in projection assembly (data not shown). Since exsFB null mutant spores have not been shown to have strong phenotypes (Sylvestre et al., 2005), we did not further characterize ExsFB-GFP-bearing cells by TEM. 


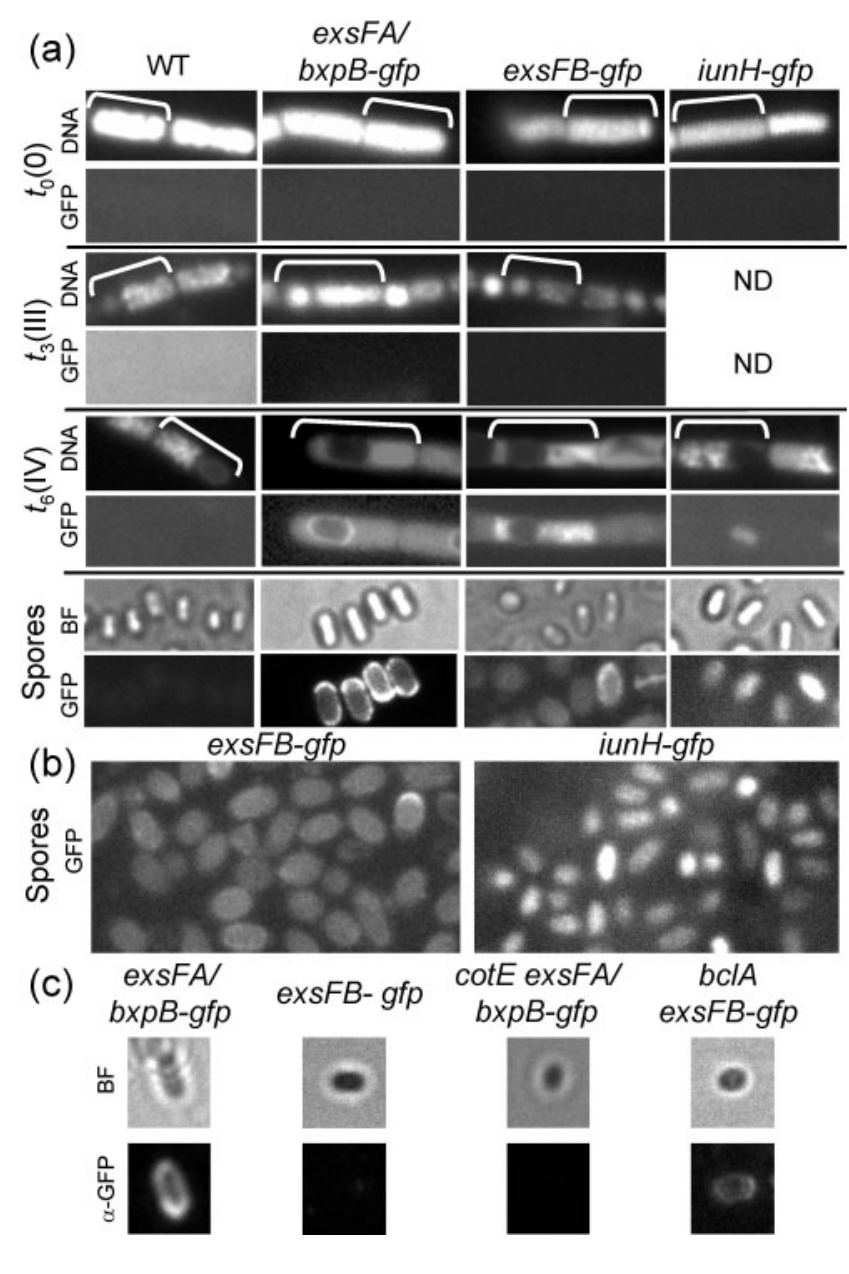

We did not detect fluorescence in cells from strain RG151 (bearing the ExsFA/BxpB-GFP fusion) at $3 \mathrm{~h}$ after the onset of sporulation (Fig. 5a). At $5 \mathrm{~h}$, we found that fluorescence was dispersed throughout the mother cell and excluded from the forespore (data not shown). After $6 \mathrm{~h}$, we detected fluorescence in both a ring around the forespore as well as dispersed throughout the mother cell (Fig. 5a). Released spores bearing ExsFA/BxpB-GFP (from strain RG151) showed rings of fluorescence that surrounded the spores and were more intense at the caps (Fig. 5 a, bottom). In about $60 \%$ of spores, we saw that one cap was brighter than the other.

To detect fluorescence due to ExsFB-GFP, we sporulated cells bearing this fusion (strain RG155) at room temperature using $2 \times$ SG medium, as we did not detect fluorescence during culture at $37{ }^{\circ} \mathrm{C}$ in DSM (data not shown). Culturing cells at a decreased temperature has been shown to facilitate detection of certain fusions in both in B. subtilis and B. anthracis (Kim et al., 2006; Mallozzi et al., 2008; van Ooij et al., 2004). Similarly to the case of ExsFA/BxpB-GFP, we first detected fluorescence in ExsFBGFP-bearing cells (RG155) as a dispersed signal in the mother cell, beginning at stage IV of sporulation (where the stage of sporulation was determined by visualization of
Fig. 5. Fluorescence microscopic analysis of ExsFA/BxpB-GFP, ExsFB-GFP and lunH-GFP. (a) Fluorescence microscopic localization of fusion proteins during sporulation. Cells from strains RG1 (wild-type; WT), RG151 (exsFA/bxpB-gfp) and RG130 (iunH-gfp) were cultured in DSM broth at $37{ }^{\circ} \mathrm{C}$ and harvested at $0(t 0), 3(t 3), 6(t 6)$ and $24 \mathrm{~h}$ (Spores) after the onset of sporulation. Cells from strain RG155 (exsFB-gfp) were cultured in $2 \times \mathrm{SG}$ broth at $25{ }^{\circ} \mathrm{C}$, harvested at various times and staged by analysis of chromosome morphology. DNA staining (DNA) and GFP epifluorescence (GFP) are shown for each time point, and DNA staining was used to determine whether cells had transitioned to sporulation $\left[t_{0}\right.$ or stage $0(0)$ ] or progressed to stage III (III) or stage IV (IV). Brackets indicate individual sporangia. GFP epifluorescence (GFP) and bright-field (BF) images of released spores are also shown for all strains. (b) Larger fields showing fluorescence microscopic localization of ExsFB-GFP and lunH-GFP. Additional examples of the solid oval fluorescence pattern of these two fusion proteins, without corresponding brightfield images, for spores of strain RG155 (exsFB-gfp) and RG130 (iunH-gfp) are shown. (c) Immunofluorescence detection of fusion proteins in released spores from strains RG151 (exsFA/bxpBgfp), RG155 (exsFB-gfp), RG157 (cotE exsFA/bxpB-gfp) and RG169 (bclA exsFB-gfp). Data shown are representative of a minimum of 150 cells observed for each sample and time point. We judged the immunostaining to be positive if at least $90 \%$ of the cells showed fluorescence. All negative control experiments showed fluorescence in less than $10 \%$ of cells. Spores from strains RG155 and RG169 were cultured in DSM at $25{ }^{\circ} \mathrm{C}$. Bright-field (BF) and anti-GFP immunofluorescence ( $\alpha$-GFP) are shown for each. Images were not acquired (ND) for RG130 (iunH-gfp) after $3 \mathrm{~h}$ of sporulation.

chromosome morphology using a DNA stain, and by phase-contrast microscopy) (Fig. 5a and data not shown). We noted that fluorescence was excluded from the forespore during stage IV of sporulation, which is the time when the forespore is no longer metabolically active (Losick et al., 1986). In contrast, released spores bearing the ExsFB-GFP fusion (from strain RG155) had either a solid oval of fluorescence or, occasionally, rings (in 17 of 380 spores observed) of fluorescence that surrounded the spores (Fig. 5a, b, and data not shown). This is in striking contrast to what we and others have seen with fusions of coat protein genes to GFP, in both B. anthracis and $B$. subtilis, where the patterns of localization are usually rings, and sometimes caps or other structures that suggest incomplete rings, but never solid ovals (Bauer et al., 1999; Eichenberger et al., 2003; Kim et al., 2006; Mallozzi et al., 2008; McPherson et al., 2005; van Ooij et al., 2004). We note that the timing of the appearance of ExsFB-GFP fluorescence, just described, is inconsistent with the possibility that ExsFB-GFP is synthesized in the spore core. The view that ExsFB is synthesized in the mother cell is further supported by the presence of a candidate $\sigma^{\mathrm{K}}$ driven promoter upstream of exsFB (Steichen et al., 2005). Therefore, although ExsFB-GFP fluorescence appears as a solid oval, it is highly unlikely that this fluorescence emanates from the spore interior. 
To ensure that the fluorescence patterns of ExsFA/BxpBGFP and ExsFB-GFP are truly distinct, we reexamined the more intense ExsFA/BxpB-GFP signal with the camera sensitivity reduced. The signal remained a ring at all intensities. Likewise, increasing the camera sensitivity did not result in rings of ExsFB-GFP fluorescence. Therefore, the fluorescence patterns of ExsFA/BxpB-GFP and ExsFBGFP are distinct.

To directly compare the timing of assembly of the two fusion proteins, in a separate experiment we also carried out sporulation of the ExsFA/BxpB-GFP-bearing strain (RG151) and the ExsFB-GFP-bearing strain (RG155) at room temperature (in $2 \times$ SG medium). Sporulation of RG151 cells at room temperature did not detectably alter the fluorescence pattern of ExsFA/BxpB-GFP, which formed a ring, as it did during sporulation at $37^{\circ} \mathrm{C}$. From this analysis, we found that fluorescence due to ExsFB-GFP appeared several hours later than fluorescence due to ExsFA/BxpB-GFP (data not shown). Given that sporulation is relatively slow at this temperature, the biological significance of this difference in timing is unclear.

To learn whether the unusual solid oval localization pattern of ExsFB-GFP might be a property of other exosporium-associated proteins, we also analysed the localization of a fusion of GFP to the putative nucleoside hydrolase, IunH (encoded by a gene currently annotated as BA2888), which has also been shown to fractionate with the exosporium (Redmond et al., 2004; Todd et al., 2003) and which we also identified in a previous proteomic study as a spore-associated protein (Lai et al., 2003). We found that the pattern of fluorescence in spores bearing iun $H-g f p$ (strain RG130) was very similar to that of the exsFB-gfpbearing spores from strain RG155 (Fig. 5a, b), although in about $3 \%$ of spores the fluorescence of the solid oval was much brighter than the rest ( 6 out of 200 spores observed) (Fig. 5a, b, and data not shown).

To interpret the solid oval patterns of ExsFB-GFP and IunH-GFP fluorescence in terms of subcellular localization of the respective proteins, we first considered the possibility that the ring-like appearance of typical spore protein-GFP fusions could be ascribed to the geometry of the microscope set-up. Because the 2D image (a ring) captured by the camera is actually due to a projection of a 3D image (a shell), the edges of the image show a greater amount of image intensity, per pixel, than does the interior. Therefore, a possible explanation for the disk of fluorescence would be that, rather than being confined to a thin shell, ExsFB-GFP and IunH-GFP form a very thick layer, as they might if they resided in the interspace. If this were true, then a significant fraction (if not all) of these fusion proteins would be hidden underneath the exosporium. Further support for this interpretation comes from the observation that GFP fluorescence is excluded from the forespore in stage IV exsFB-gfp-bearing cells (Fig. 5a). These data indicate that ExsFB-GFP is not in the forespore prior to stage IV, when forespore metabolism has already ceased (Losick et al., 1986). Therefore, it is extremely unlikely that the forespore-associated GFP in these cells is due to ExsFBGFP in the core. Much more likely, ExsFB-GFP surrounds the core.

To clarify the locations of ExsFA/BxpB-GFP and ExsFBGFP, we first determined whether they could be detected on the spore surface, using IFM. We mixed anti-GFP antibodies with spores from either strain and visualized the resulting complexes using fluorescence microscopy. ExsFA/ BxpB-GFP-bearing spores reacted with anti-GFP antibodies, as expected from the known basal-layer location of ExsFA/BxpB (Steichen et al., 2005) and the lack of projections, due to the exsFA/bxpB-gfp allele, see above (Fig. 5c) (Steichen et al., 2005). In contrast, anti-GFP antibodies did not react with ExsFB-GFP-bearing spores (from strain RG155, Fig. 5c).

To investigate the locations of these proteins further, we applied anti-GFP antibodies to spores bearing either fusion, but in which the exosporium was also incompletely assembled, due to a mutation in $\cot E$ (from strains RG157 and RG158). As in all our IFM analyses, we examined a minimum of 150 cells. In separate work, we have shown that deletion of $\cot E$ results in spores that lack the exosporium (Giorno et al., 2007). However, those experiments do not reveal whether CotE controls interspace formation. Spores bearing ExsFA/BxpB-GFP and a mutation in cotE (from strain RG157) did not react with antiGFP antibodies (and did not show fluorescence due to GFP) (Fig. 5c), as we expected. Interestingly, we also found that we did not detect ExsFB-GFP in spores of a strain also bearing the $\cot E$ mutation (in strain RG158), by application of either anti-GFP antibodies or, more importantly, GFP fluorescence (data not shown). Therefore, detection of ExsFB-GFP is CotE-dependent, consistent with a location for the fusion in the interspace, the exosporium, or both.

These data above do not exclude the possibility that ExsFB also is present within the exosporium basal layer. If it were, localization by IFM might be inhibited by the presence of the BclA projections. To address this, we analysed $b c l A$ exsFB- $g f p$ spores (from strain RG169) by IFM. We detected fluorescence around the spore (Fig. 5c). The pattern of immunofluorescence from strain RG169 spores was a discontinuous ring, in contrast to the continuous ring of ExsFA-GFP immunofluorescence (in strain RG151). We interpret these data to suggest that ExsFB is present in both the basal layer and the interspace.

\section{DISCUSSION}

An important question in B. anthracis spore assembly is the timing and control of BclA deposition. Earlier investigations have shown that while most $\mathrm{BclA}$ assembly requires ExsFA/BxpB, a significant fraction of BclA assembles in an ExsFA/BxpB-independent manner, and that ExsFA/BxpBdependent BclA assembly is needed for formation of the 
projections (Steichen et al., 2005; Sylvestre et al., 2005). We also found this and, additionally, we showed that BclA accumulates at the mother cell pole in $\operatorname{exs} F A / b x p B$ forespores. Therefore, the fraction of BclA that localizes independently of ExsFA/BxpB appears on the mother-cellproximal portion of the exosporium that forms early in sporulation, and under the direction of CotE (Giorno et al., 2007; Ohye \& Murrell, 1973). This is likely the first portion of the exosporium to be assembled (Giorno et al., 2007). Interestingly, this region of the exosporium is biochemically distinct from the rest of the exosporium, as it lacks alanine racemase and its assembly is ExsY-independent (Steichen et al., 2007). Taken together, these data appear to suggest that exosporium assembly is a two-step process. In the first step, CotE directs deposition of a biochemically specialized patch of the basal layer onto the forespore pole closest to the mother cell midpoint. In the second step, ExsY directs the remainder of the polymerization of the sheet of exosporium, an event that terminates when the exosporium shell closes on itself (Steichen et al., 2007). The factor(s) directing assembly of ExsFA/BxpB-independent $\mathrm{BclA}$ remains unknown. However, ExsFB is a plausible candidate, since exsFA/bxpB exsFB double mutant spores assemble less BclA than $\operatorname{exs} F A / \operatorname{sxp} B$ mutant spores (Sylvestre et al., 2005).

We detected a modest germination defect in exsFA/bxpB mutant spores by multiple assays, indicating at least one role for this protein beyond mediating BclA deposition. The finding of a germination defect is in contrast to an earlier finding showing that both germination and outgrowth are accelerated in mutant spores (Steichen et al., 2005). We do not know the basis for this discrepancy, but it is plausibly due to differences in the physical set-up of our experimental systems. We note that while similar media were used to measure germination in one case, Steichen et al. (2005) used a flow chamber system, while we used assays in which germinant was not replenished during the experiment (Harwood \& Cutting, 1990). Possibly, the constant flow of nutrient has a marked affect on germination in the $\operatorname{exs} F A / \operatorname{sxp} B$ mutant that cannot be observed when the germinant is given in a single dose.

We found that ExsFA/BxpB is not needed for the typical presentation of $B$. anthracis infection in two models. This is consistent with previous findings demonstrating that even without BclA, spores from either the attenuated Sterne or the virulent Ames backgrounds can still cause infection (Bozue et al., 2007a; Brahmbhatt et al., 2007; Sylvestre et al., 2002). Importantly, it extends those results by demonstrating the dispensability of the projections (or nap) in an entirely separate manner, and using an additional route of infection (the Guinea pig inhalational challenge). These data also are consistent with our previous finding that spores lacking the exosporium, due to a mutation in the coat protein gene $\cot E$, are fully virulent in two animal models (Giorno et al., 2007). These experiments raise an important caution; while defences and therapeutics targeting the exosporium will be very useful, we should not rely on them exclusively, since this structure may be dispensable (Giorno et al., 2007). Rather, we must prepare for events using spores both with and without projections.

Although we did not detect an effect of ExsFA/BxpB on disease, the exosporium may still have a role in interactions with the host. For example, it has been shown recently that the exosporium provides a degree of protection against macrophages (Weaver et al., 2007). Also, the presence of BclA may be necessary for targeting spores to macrophages, as it decreases spore adherence to epithelial, fibroblast and endothelial cells (Bozue et al., 2007b). Therefore, at least under certain circumstances, the exosporium could affect the natural disease process in ways not detected in our assays. Exosporium proteins or the genes encoding these proteins may also be useful as subunits in an improved anthrax vaccine, as suggested by several studies (Brossier et al., 2002; Cybulski et al., 2008; Enkhtuya et al., 2006; Hahn et al., 2006). Therefore, interactions between the host and exosporium proteins are likely to be important to future therapeutics.

If the projections are not always needed for disease, then what is their function? It is plausible that the projections have roles in resistance or attachment, in the soil or some other ecological niche. B. anthracis maintains a highly complex series of spore protective structures, apparently largely dedicated to survival outside the host, in spite of its adaptation to animal hosts. It may be challenging to identify these additional roles. An example of an organism that likely uses BclA for a purpose other than disease is the non-pathogenic organism Bacillus licheniformis, a close relative of $B$. subtilis that does not have an exosporium but which possesses an orthologue of BclA (M. Mallozzi \& A. Driks, unpublished results). Preliminary phylogenetic analysis suggests that $\mathrm{BclA}$ was, in this case, acquired by horizontal gene transfer (H. Qin \& A. Driks, unpublished results).

Most coat and exosporium genes do not have paralogues. $\operatorname{exs} F A / \operatorname{bxp} B$ and exsFB are exceptions. Making this set of genes even more unusual, some $B$. cereus-group strains possess a third paralogue that differs from exsFA/bxpB and $\operatorname{exs} F B$ at least as much as those two genes differ from each other. B. anthracis has only two paralogues, as do 19 other strains, three strains have only one paralogue, and $B$. cereus $\mathrm{E} 33 \mathrm{~L}$ contains three paralogues. Interestingly, in $B$. cereus $\mathrm{E} 33 \mathrm{~L}$ two of the paralogues are on the chromosome and one is plasmid-encoded. Possibly, these variations result in adaptive changes in exosporium structure and function.

Our data argue that ExsFB-GFP and IunH-GFP do not precisely colocalize with the exosporium basal layer. We suggest the possibility that ExsFB and IunH reside in the interspace. At present, this localization is not definitive. Future experiments to support these data and to uncover additional possible interspace proteins may help clarify the function of this poorly understood spore compartment. 


\section{ACKNOWLEDGEMENTS}

The authors thank Kathy Kuehl [Pathology Department, United States Army Medical Research Institute of Infectious Diseases (USAMRIID)] for preparation of electron microscope samples and Sarah Norris (USAMRIID) for statistical analysis. We thank Terri Koehler (University of Texas, Houston) for the kind gift of CP-51, plasmids and strains, and for valuable advice. We thank Peter McKenney and Patrick Eichenberger for important input into this study. Funding was provided by the NIH (AI53365, A.D.) and the US Army Medical Research and Materiel Command under Projects 02-4-5C-018 (J. B.), 02-4-5C-023 (S.W.) and 04-0-IL-002 (S.W.) and an In-House Laboratory Innovative Research Award from the Department of the Army under Project 92489 (J.B.). Research was conducted in compliance with the Animal Welfare Act and other federal statutes and regulations relating to animals and experiments involving animals and adheres to principles stated in the Guide for the Care and Use of Laboratory Animals (Institute of Laboratory Animal Resources et al., 1996). The facility in which this research was conducted is fully accredited by the Association for Assessment and Accreditation of Laboratory Animal Care International. Opinions, interpretations, conclusions, and recommendations are those of the authors and are not necessarily endorsed by the US Army.

\section{REFERENCES}

Alibek, K. (1999). Biohazard. New York: Random House.

Aronson, A. I. \& Fitz-James, P. (1976). Structure and morphogenesis of the bacterial spore coat. Bacteriol Rev 40, 360-402.

Basu, S., Kang, T. J., Chen, W. H., Fenton, M. J., Baillie, L., Hibbs, S. \& Cross, A. S. (2007). Role of Bacillus anthracis spore structures in macrophage cytokine responses. Infect Immun 75, 2351-2358.

Bauer, T., Little, S., Stöver, A. G. \& Driks, A. (1999). Functional regions of the Bacillus subtilis spore coat morphogenetic protein CotE. J Bacteriol 181, 7043-7051.

Boydston, J. A., Chen, P., Steichen, C. T. \& Turnbough, C. L., Jr (2005). Orientation within the exosporium and structural stability of the collagen-like glycoprotein BclA of Bacillus anthracis. J Bacteriol 187, 5310-5317.

Boydston, J. A., Yue, L., Kearney, J. F. \& Turnbough, C. L., Jr (2006). The ExsY protein is required for complete formation of the exosporium of Bacillus anthracis. J Bacteriol 188, 7440-7448.

Bozue, J. A., Parthasarathy, N., Phillips, L. R., Cote, C. K., Fellows, P. F., Mendelson, I., Shafferman, A. \& Friedlander, A. M. (2005). Construction of a rhamnose mutation in Bacillus anthracis affects adherence to macrophages but not virulence in guinea pigs. Microb Pathog 38, 1-12.

Bozue, J., Cote, C. K., Moody, K. L. \& Welkos, S. L. (2007a). Fully virulent Bacillus anthracis does not require the immunodominant protein BclA for pathogenesis. Infect Immun 75, 508-511.

Bozue, J., Moody, K. L., Cote, C. K., Stiles, B. G., Friedlander, A. M., Welkos, S. L. \& Hale, M. L. (2007b). Bacillus anthracis spores of the bclA mutant exhibit increased adherence to epithelial, fibroblast, and endothelial cells but not macrophages. Infect Immun 75, 4498-4505.

Brahmbhatt, T. N., Janes, B. K., Stibitz, E. S., Darnell, S. C., Sanz, P., Rasmussen, S. B. \& O'Brien, A. D. (2007). Bacillus anthracis exosporium protein BclA affects spore germination, interaction with extracellular matrix proteins, and hydrophobicity. Infect Immun $\mathbf{7 5}$, 5233-5239.

Brossier, F., Levy, M. \& Mock, M. (2002). Anthrax spores make an essential contribution to vaccine efficacy. Infect Immun $\mathbf{7 0}$, $661-664$
Catalano, F. A., Meador-Parton, J., Popham, D. L. \& Driks, A. (2001). Amino acids in the Bacillus subtilis morphogenetic protein SpoIVA with roles in spore coat and cortex formation. J Bacteriol 183, 1645-1654.

Chada, V. G., Sanstad, E. A., Wang, R. \& Driks, A. (2003). Morphogenesis of Bacillus spore surfaces. J Bacteriol 185, 6255-6261.

Cown, W. B., Kethley, T. W. \& Fincher, E. L. (1957). The critical-orifice liquid impinger as a sampler for bacterial aerosols. Appl Microbiol 5, 119-124.

Cybulski, R. J., Jr, Sanz, P., McDaniel, D., Darnell, S., Bull, R. L. \& O'Brien, A. D. (2008). Recombinant Bacillus anthracis spore proteins enhance protection of mice primed with suboptimal amounts of protective antigen. Vaccine 26, 4927-4939.

Dowd, M. M., Orsburn, B. \& Popham, D. L. (2008). Cortex peptidoglycan lytic activity in germinating Bacillus anthracis spores. J Bacteriol 190, 4541-4548.

Eichenberger, P., Jensen, S. T., Conlon, E. M., van Ooij, C., Silvaggi, J., González-Pastor, J. E., Fujita, M., Ben-Yehuda, S., Stragier, P. \& other authors (2003). The $\sigma^{\mathrm{E}}$ regulon and the identification of additional sporulation genes in Bacillus subtilis. J Mol Biol 327, 945-972.

Enkhtuya, J., Kawamoto, K., Kobayashi, Y., Uchida, I., Rana, N. \& Makino, S. (2006). Significant passive protective effect against anthrax by antibody to Bacillus anthracis inactivated spores that lack two virulence plasmids. Microbiology 152, 3103-3110.

Fotiadis, D., Scheuring, S., Muller, S. A., Engel, A. \& Muller, D. J. (2002). Imaging and manipulation of biological structures with the AFM. Micron 33, 385-397.

Fox, A., Stewart, G. C., Wallera, L. N., Fox, K. F., Harley, W. M. \& Price, R. L. (2003). Carbohydrates and glycoproteins of Bacillus anthracis and related bacilli: targets for biodetection. J Microbiol Methods 54, 143-152.

Friedlander, A. M., Welkos, S. L., Pitt, M. L., Ezzell, J. W., Worsham, P. L., Rose, K. J., Ivins, B. E., Lowe, J. R., Howe, G. B. \& other authors (1993). Postexposure prophylaxis against experimental inhalation anthrax. J Infect Dis 167, 1239-1243.

Fritze, D. (2004). Taxonomy of the genus Bacillus and related genera: the aerobic endospore-forming bacteria. Phytopathology 94, 1245-1248.

Giorno, R., Bozue, J., Cote, C., Wenzel, T., Moody, K. S., Mallozzi, M., Ryan, M., Wang, R., Zielke, R. \& other authors (2007). Morphogenesis of the Bacillus anthracis spore coat. J Bacteriol 189, 691-705.

Hahn, U. K., Boehm, R. \& Beyer, W. (2006). DNA vaccination against anthrax in mice - combination of anti-spore and anti-toxin components. Vaccine 24, 4569-4571.

Harwood, C. R. \& Cutting, S. M. (1990). Molecular Biological Methods for Bacillus. Chichester, UK: John Wiley.

Holt, S. C. \& Leadbetter, E. R. (1969). Comparative ultrastructure of selected aerobic spore-forming bacteria: a freeze-etching study. Bacteriol Rev 33, 346-378.

Institute of Laboratory Animal Resources, Commission on Life Sciences, \& National Research Council (1996). Guide for the Care and Use of Laboratory Animals. Washington, DC: National Academy Press.

Ivins, B. E., Welkos, S. L., Knudson, G. B. \& Little, S. F. (1990). Immunization against anthrax with aromatic compound-dependent (Aro $^{-}$) mutants of Bacillus anthracis and with recombinant strains of Bacillus subtilis that produce anthrax protective antigen. Infect Immun 58, 303-308.

Ivins, B. E., Fellows, P. F. \& Nelson, G. O. (1994). Efficacy of a standard human anthrax vaccine against Bacillus anthracis spore challenge in guinea-pigs. Vaccine 12, 872-874.

Kim, H., Hahn, M., Grabowski, P., McPherson, D. C., Wang, R., Ferguson, C., Eichenberger, P. \& Driks, A. (2006). The Bacillus subtilis spore coat protein interaction network. Mol Microbiol 59, 487-502. 
Koch, R. (1876). The etiology of anthrax, based on the life history of Bacillus anthracis. Beitr Biol Pflanz 2, 277-310.

Koehler, T. M., Dai, Z. \& Kaufman-Yarbray, M. (1994). Regulation of the Bacillus anthracis protective antigen gene: $\mathrm{CO}_{2}$ and a trans-acting element activate transcription from one of two promoters. J Bacteriol 176, 586-595.

La Duc, M. T., Satomi, M. \& Venkateswaran, K. (2004). Bacillus odysseyi sp. nov., a round-spore-forming bacillus isolated from the Mars Odyssey spacecraft. Int J Syst Evol Microbiol 54, 195-201.

Lai, E.-M., Phadke, N. D., Kachman, M. T., Giorno, R. S. V., Vazquez, J. A., Maddock, J. R. \& Driks, A. (2003). Proteomic analysis of the spore coats of Bacillus subtilis and Bacillus anthracis. J Bacteriol 185, 1443-1454.

Leighton, T. J. \& Doi, R. H. (1971). The stability of messenger ribonucleic acid during sporulation in Bacillus subtilis. J Biol Chem 246, 3189-3195.

Lemon, K. P. \& Grossman, A. D. (1998). Localization of bacterial DNA polymerase: evidence for a factory model of replication. Science 282, 1516-1519.

Little, S. F. \& Knudson, G. B. (1986). Comparative efficacy of Bacillus anthracis live spore vaccine and protective antigen vaccine against anthrax in the guinea pig. Infect Immun 52, 509-512.

Losick, R., Youngman, P. \& Piggot, P. J. (1986). Genetics of endospore formation in Bacillus subtilis. Annu Rev Genet 20, 625-669.

Mallozzi, M., Bozue, J., Giorno, R., Moody, K. S., Slack, A., Cote, C., Qiu, D., Wang, R., McKenney, P. \& other authors (2008). Characterization of a Bacillus anthracis spore coat-surface protein that influences coat-surface morphology. FEMS Microbiol Lett 289, $110-117$.

Mann, H. B. \& Whitney, D. R. (1947). On a test of whether one of two random variables is stochastically larger than the other. Ann Math Stat 18, 50-60.

Matz, L. L., Beaman, T. C. \& Gerhardt, P. (1970). Chemical composition of exosporium from spores of Bacillus cereus. J Bacteriol 101, 196-201.

May, K. R. (1973). The collision nebulizer, description, performance, and applications. J Aerosol Sci 4, 235-243.

McPherson, D. C., Kim, H., Hahn, M., Wang, R., Grabowski, P., Eichenberger, P. \& Driks, A. (2005). Characterization of the Bacillus subtilis spore coat morphogenetic protein CotO. J Bacteriol 187, 8278-8290.

Mendelson, I., Tobery, S., Scorpio, A., Bozue, J., Shafferman, A. \& Friedlander, A. M. (2004). The NheA component of the non-hemolytic enterotoxin of Bacillus cereus is produced by Bacillus anthracis but is not required for virulence. Microb Pathog 37, 149-154.

Mock, M. \& Fouet, A. (2001). Anthrax. Annu Rev Microbiol 55, 647-671.

Moir, A., Corfe, B. M. \& Behravan, J. (2002). Spore germination. Cell Mol Life Sci 59, 403-409.

Nicholson, W. L. (2002). Roles of Bacillus endospores in the environment. Cell Mol Life Sci 59, 410-416.

Ohye, D. F. \& Murrell, W. G. (1973). Exosporium and spore coat formation in Bacillus cereus T. J Bacteriol 115, 1179-1190.

Oliva, C. R., Swiecki, M. K., Griguer, C. E., Lisanby, M. W., Bullard, D. C., Turnbough, C. L., Jr \& Kearney, J. F. (2008). The integrin Mac-1 (CR3) mediates internalization and directs Bacillus anthracis spores into professional phagocytes. Proc Natl Acad Sci U S A 105, 1261-1266.

Perez-Casal, J., Caparon, M. G. \& Scott, J. R. (1991). Mry, a transacting positive regulator of the $\mathrm{M}$ protein gene of Streptococcus pyogenes with similarity to the receptor proteins of two-component regulatory systems. J Bacteriol 173, 2617-2624.
Plomp, M., Leighton, T., Wheeler, K. E. \& Malkin, A. J. (2004). The high-resolution architecture and structural dynamics of Bacillus spores. Biophys J 88, 603-608.

Pogliano, K., Harry, E. \& Losick, R. (1995). Visualization of the subcellular location of sporulation proteins in Bacillus subtilis using immunofluorescence microscopy. Mol Microbiol 18, 459-470.

Popham, D. L. (2002). Specialized peptidoglycan of the bacterial endospore: the inner wall of the lockbox. Cell Mol Life Sci 59, 426-433.

Redmond, C., Baillie, L. W., Hibbs, S., Moir, A. J. \& Moir, A. (2004). Identification of proteins in the exosporium of Bacillus anthracis. Microbiology 150, 355-363.

Rety, S., Salamitou, S., Garcia-Verdugo, I., Hulmes, D. J., Le Hegarat, F., Chaby, R. \& Lewit-Bentley, A. (2005). The crystal structure of the Bacillus anthracis spore surface protein BclA shows remarkable similarity to mammalian proteins. J Biol Chem 280, 43073-43078.

Sambrook, J., Fritsch, E. F. \& Maniatis, T. (1989). Molecular Cloning: a Laboratory Manual, 2nd edn. Cold Spring Harbor, NY: Cold Spring Harbor Laboratory.

Setlow, P. (2006). Spores of Bacillus subtilis: their resistance to and killing by radiation, heat and chemicals. J Appl Microbiol 101, 514-525.

Shao, Z., Mou, J., Czajkowsky, D. M., Yang, J. \& Yuan, J. Y. (1996). Biological atomic force microscopy: what is achieved and what is needed. Adv Phys 45, 1-86.

Shatalin, K. Y. \& Neyfakh, A. A. (2005). Efficient gene inactivation in Bacillus anthracis. FEMS Microbiol Lett 245, 315-319.

Steichen, C., Chen, P., Kearney, J. F. \& Turnbough, C. L., Jr (2003). Identification of the immunodominant protein and other proteins of the Bacillus anthracis exosporium. J Bacteriol 185, 1903-1910.

Steichen, C. T., Kearney, J. F. \& Turnbough, C. L., Jr (2005). Characterization of the exosporium basal layer protein $\mathrm{BxpB}$ of Bacillus anthracis. J Bacteriol 187, 5868-5876.

Steichen, C. T., Kearney, J. F. \& Turnbough, C. L., Jr (2007). Nonuniform assembly of the Bacillus anthracis exosporium and a bottle cap model for spore germination and outgrowth. Mol Microbiol 64, 359-367.

Sylvestre, P., Couture-Tosi, E. \& Mock, M. (2002). A collagen-like surface glycoprotein is a structural component of the Bacillus anthracis exosporium. Mol Microbiol 45, 169-178.

Sylvestre, P., Couture-Tosi, E. \& Mock, M. (2003). Polymorphism in the collagen-like region of the Bacillus anthracis BclA protein leads to variation in exosporium filament length. J Bacteriol 185, 1555-1563.

Sylvestre, P., Couture-Tosi, E. \& Mock, M. (2005). Contribution of ExsFA and ExsFB proteins to the localization of BclA on the spore surface and to the stability of the Bacillus anthracis exosporium. $J$ Bacteriol 187, 5122-5128.

Thompson, B. M., Waller, L. N., Fox, K. F., Fox, A. \& Stewart, G. C. (2007). The BclB glycoprotein of Bacillus anthracis is involved in exosporium integrity. J Bacteriol 189, 6704-6713.

Thorne, C. B. (1968). Transduction in Bacillus cereus and Bacillus anthracis. Bacteriol Rev 32, 358-361.

Todd, S. J., Moir, A. J., Johnson, M. J. \& Moir, A. (2003). Genes of Bacillus cereus and Bacillus anthracis encoding proteins of the exosporium. J Bacteriol 185, 3373-3378.

van Ooij, C., Eichenberger, P. \& Losick, R. (2004). Dynamic patterns of subcellular protein localization during spore coat morphogenesis in Bacillus subtilis. J Bacteriol 186, 4441-4448.

Vary, P. S. (1994). Prime time for Bacillus megaterium. Microbiology 140, 1001-1013.

Waller, L. N., Stump, M. J., Fox, K. F., Harley, W. M., Fox, A., Stewart, G. C. \& Shahgholi, M. (2005). Identification of a second collagen-like glycoprotein produced by Bacillus anthracis and demonstration of associated spore-specific sugars. J Bacteriol 187, 4592-4597. 
Wang, R., Krishnamurthy, S. N., Jeong, J. S., Driks, A., Mehta, M. \& Gingras, B. A. (2007). Fingerprinting species and strains of Bacilli spores by distinctive coat surface morphology. Langmuir 23, 10230-10234.

Warth, A. D., Ohye, D. F. \& Murrell, W. G. (1963). The composition and structure of bacterial spores. J Cell Biol 16, 579-592.

Weaver, J., Kang, T. J., Raines, K. W., Cao, G. L., Hibbs, S., Tsai, P., Baillie, L., Rosen, G. M. \& Cross, A. S. (2007). Protective role of
Bacillus anthracis exosporium in macrophage-mediated killing by nitric oxide. Infect Immun 75, 3894-3901.

Welkos, S. L., Cote, C. K., Rea, K. M. \& Gibbs, P. H. (2004). A microtiter fluorometric assay to detect the germination of Bacillus anthracis spores and the germination inhibitory effects of antibodies. J Microbiol Methods 56, 253-265.

Edited by: M. Hecker 